\title{
HIGHLY RESPONSIVE AND ACCURATE TEMPERATURE MEASUREMENTS IN ORTHOGONAL CUTTING THROUGH INNOVATIVE SINGLE LEG THERMOCOUPLE
}

\author{
I. Hamm ${ }^{1,2 *}$, F. Rossi ${ }^{1}$, G. Poulachon ${ }^{1}$, B. Marcon ${ }^{1}$, H. Birembaux¹, N. Maury², S. Valadon ${ }^{2}$, F. Labarthe $^{2}$ \\ ${ }^{1}$ Arts et Metiers Institute of Technology, LABOMAP, HESAM Universite, F-71250 Cluny, France \\ ${ }^{2}$ Airbus Operations SAS, 31200 Toulouse, France \\ ${ }^{\star}$ Corresponding author; e-mail: ivan.hamm@ensam.eu
}

\begin{abstract}
During machining, most of the thermal sources are resulting from the conversion of mechanical energy during the chip shearing mechanism and the intense frictions between the tool, the chip, and the machined surface. Thermal gradients are high and localized, especially for low thermal diffusivity material like titanium alloys. Moreover, heat rates come close to few million degrees per second in the shearing zones. Even though several authors performed thermography techniques to determine the temperature distribution into the machined material, their results remain underestimated due to experimental limitations. In this research, a new temperature measurement technique has been developed based on a single wire thermocouple to measure at one exact location both the temperature and the heating rate during orthogonal cutting test. The tests are performed with uncut chip thicknesses of $0.020 \mathrm{~mm}$ and $0.100 \mathrm{~mm}$ and with a cutting speed of $120 \mathrm{~m} / \mathrm{min}$ with two different cutting angles. Results are discussed and compared to prior studies.
\end{abstract}

\section{Keywords:}

Temperature measurement; Ti-6Al-4V; Orthogonal cutting; Heating rate

\section{INTRODUCTION}

Almost all the mechanical energy developed during machining is converted into thermal energy. For abusing machining conditions, excessive thermal energy are brought to the cutting area leading to an strong temperature increase in the different cutting areas, reducing tool life and inducing surface integrity alterations. For instance, overheating plays a significant role on the fatigue life of $\mathrm{Ti}$ $6 \mathrm{Al}-4 \mathrm{~V}$. It is therefore necessary to quantify the temperature level in machined parts accurately.

Since 1920's, many techniques have been used to measure the temperature distribution into the chip, the tool and the workpiece during interrupted cutting process as milling [Stephenson 1992] or continuous cutting process as turning. As heating rates may reach more than $10^{6} \mathrm{C} / \mathrm{s}$ in the primary shearing zone, selection of a suitable temperature measurement technique with a very low time response become an important criteria.

Thermocouples (TC) have many advantages compared to spectral radiation thermometry. According to Davies et al., [Davies 2007], TC are relatively low cost, stable and reproducible, and also fast responders $(\approx 10 \mu \mathrm{s})$.

Identification of both the temperature intensity and the heating rates during machining is a valuable information to establish the thermal heat flux as well as the heat partitions acting on the tool and the machined surface. Accurate experimental measurements allow to compare the thermal partition equations and to assess the role of each cutting process parameters on the heat generation during machining. Indeed, several methods based on analytical calculations and numerical simulations were proposed by different authors such as [Hahn 1951], [Trigger 1951], [Boothroyd 1963], [Komanduri 2000] whose models are based on the theory of a mobile heat source. In all those previous cited research cases, the predicted temperatures and those measured experimentally differ significantly due to analytical assumptions.

In this article, a new experimental setup is described precisely and used to measure accurately and with a fast response the cutting temperatures beneath the machined surface through a single leg miniaturized thermocouple welded on the sample.

In addition, the creation of a new thermocouple made of the workpiece and a micrometric single leg thermocouple has many advantage compared to the common thermocouples measurements find in the literature.

As the workpiece is part of the thermocouple:

1- The measurement is no longer invasive enabling to get access to the temperature without thermal field modification. 
2- The time response is equal to the speed of electrons in the metals, then the measurement is only limited to the acquisition device speed ( $100 \mathrm{kHz}$ in this study). There is no more time delay of thermal conduction to the hot junction, because the workpiece is part of the junction.

3- The use of a single leg thermocouple enable to have access to the temperature on a surface equivalent to the size of the wire $(25 \mu \mathrm{m})$. The material and the location of the return loop is carefully chosen to minimize the interferences.

\section{EXPERIMENTAL SETUP}

\subsection{Cutting forces and temperature measurements}

The experimental setup is described in Fig. 1. It consists of a Kistler type 9257 B dynamometer, a National Instruments 9211 module for cold junction temperature compensation, two 9215 National Instruments module for the hot junction temperature measurements and to acquire the three cutting forces. All acquisition cards were synchronized using a National Instrument 9188 slot and set with a sampling rate of $100 \mathrm{kHz}$. The 9211 module is limited to $14 \mathrm{~Hz}$ but was involved only to avoid offset problem in case of global part temperature variation far from the machining area.

The thermocouple used for temperature measurement is a type $\mathrm{K}+$ with a diameter of $25 \mu \mathrm{m}$. To avoid measurement uncertainty related to distortion in thermal field when inserted thermocouple [Attia 2002], the $\mathrm{K}+$ wire is uncoated and directly welded on the workpiece near the cutting area.

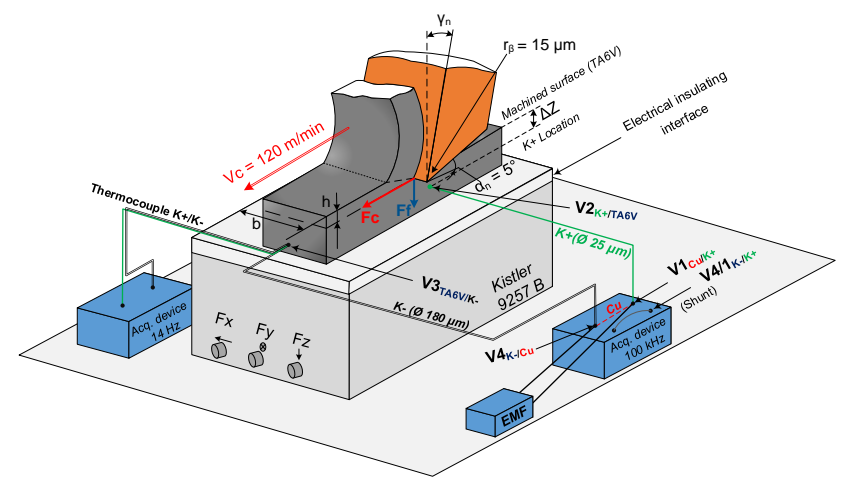

Fig. 1: Experimental scheme of the setup

In order to split the thermocouple $\mathrm{K}+/ \mathrm{K}$-, it is necessary to establish it is necessary to establish the absolute Seebeck EMF (measured electromotive force) for the materials used in the assembly as the part material acts in the thermocouple composition. Fig. 2(a) shows the electromotive forces (EMF) generated by the different pairs of materials used in the experimental device created by Seebeck effect. Fig. 2(b) shows the calculation required for the temperature measurement at the interface between the Ti-6Al-4V and the miniaturized thermocouple $\mathrm{K}+$. The EMF of interest here, being the one allowing to compute the exact temperature at the TC welding point, is the sum of each electromotive forces generated by the couples of material.

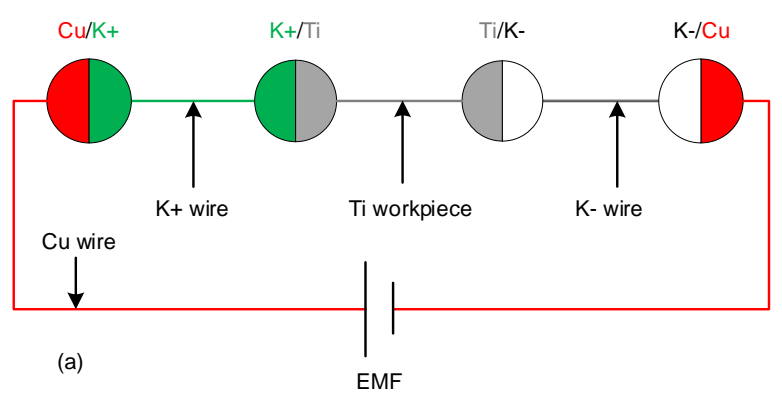

(a)

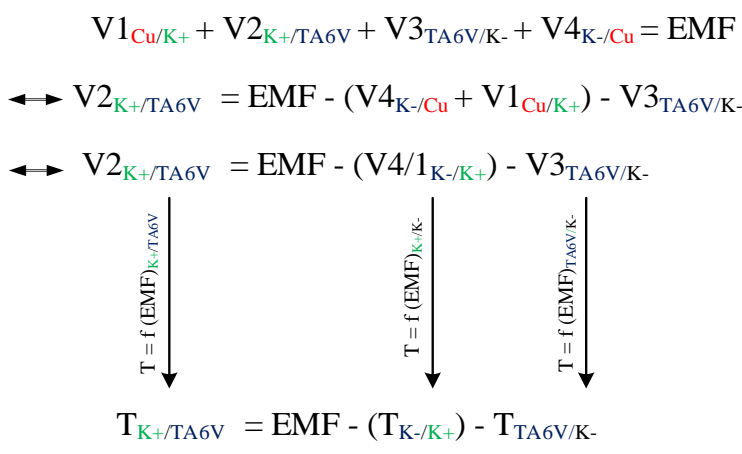

(b)

Fig. 2: (a) Schematization of thermoelectric couples (b) Thermoelectric transformation equations

\subsection{Separated legs thermocouple calibration}

In order to establish the thermoelectric transformation equations for our single leg thermocouple, a calibration setup was used and shown in Fig. 3 to determine the relation between the tension and the temperature.

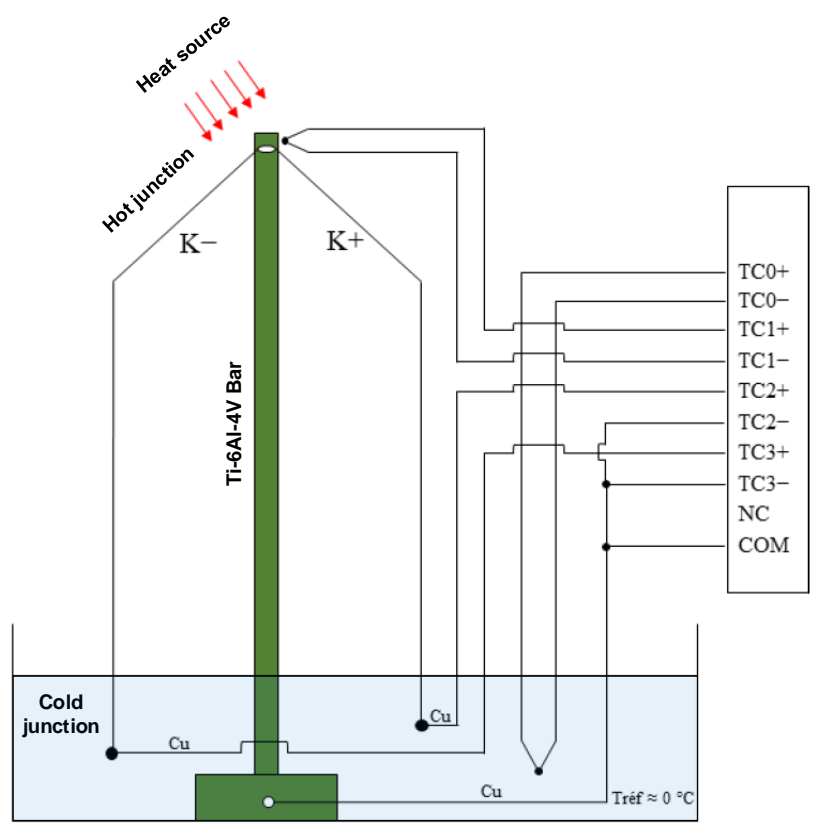

Fig. 3: Thermocouple calibration principle

Junction temperatures are measured using a National instrument 9211 module. Temperature variation are recorded while hot junction is subjected to temperature variations from $-200{ }^{\circ} \mathrm{C}$ to $900{ }^{\circ} \mathrm{C}$. 
The reference cold junction is immersed in a stirred frozen bath of distilled water at atmospheric pressure. This bath method fixes the temperature reference $\mathrm{T}_{\text {ref }}=0^{\circ} \mathrm{C}$.

Multiple couples of workpiece material, as presented in Fig. $4(\mathrm{a})-(\mathrm{b})$, and $\mathrm{K}$ thermocouples are tested and fitted with a six-order polynomial function according to eq. (1) :

$$
\mathrm{T}=\sum_{\mathrm{i}=0}^{6} \mathrm{a}_{\mathrm{i}} \cdot \mathrm{V}^{\mathrm{i}}
$$

With $\mathrm{T}$ the temperature of the measuring point $\left({ }^{\circ} \mathrm{C}\right)$, and $\mathrm{V}$ the corresponding voltage $(\mathrm{mV})$. For Ti-6Al-4V workpiece material, the identified coefficients of six-order polynomial function are described in Tab. 1.

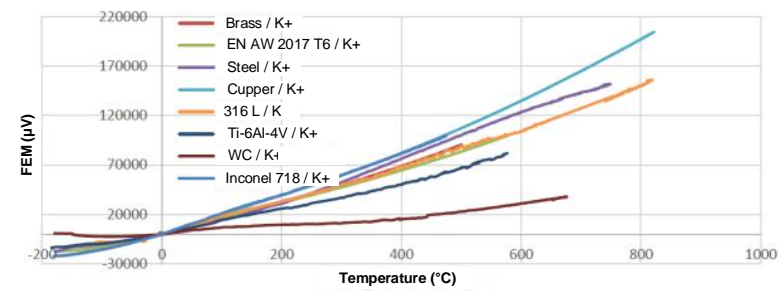

(a)

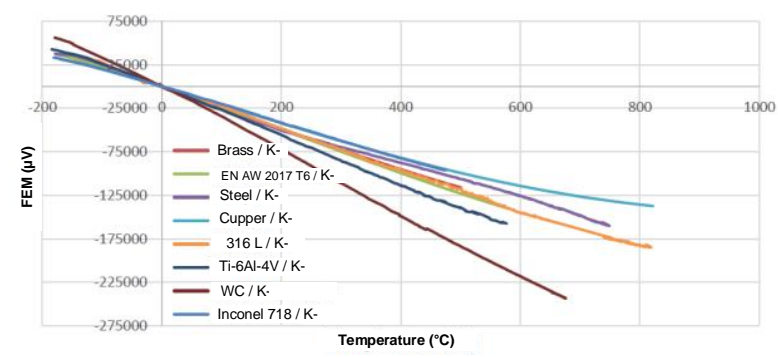

(b)

Fig. 4: Thermoelectric functions for several couple of material. (a) "Material / K+" (b) "Material / K-"

Tab. 1: Ti-6Al-4V coefficients for $K$ thermocouple

\begin{tabular}{|c|c|c|c|c|c|c|c|}
\hline Coeff. & $\mathrm{a} 0$ & $\mathrm{a} 1$ & $\mathrm{a} 2$ & $\mathrm{a} 3$ & $\mathrm{a} 4$ & $\mathrm{a} 5$ & $\mathrm{a} 6$ \\
\hline Unit & ${ }^{\circ} \mathrm{C}$ & $\mu \mathrm{V} /{ }^{\circ} \mathrm{C}$ & $\mu \mathrm{V} /{ }^{\circ} \mathrm{C}^{2}$ & $\mu \mathrm{V} /{ }^{\circ} \mathrm{C}^{3}$ & $\mu \mathrm{V} /{ }^{\circ} \mathrm{C}^{4}$ & $\mu \mathrm{V} /{ }^{\circ} \mathrm{C}^{5}$ & $\mu \mathrm{V} /{ }^{\circ} \mathrm{C}^{6}$ \\
\hline $\begin{array}{c}\mathrm{TA6V} / \\
\mathrm{K}+\end{array}$ & -236.0 & 119.8 & 0.216 & $-8 \mathrm{E}-4$ & $-1 \mathrm{E}-6$ & $7 \mathrm{E}-9$ & $-7, \mathrm{E}-12$ \\
\hline $\begin{array}{c}\mathrm{TA6V} / \\
\mathrm{K}-\end{array}$ & -215.6 & -271.8 & -0.024 & $2 \mathrm{E}-4$ & $-2 \mathrm{E}-6$ & $7 \mathrm{E}-9$ & $-5 \mathrm{E}-12$ \\
\hline
\end{tabular}

Then, thermoelectric relations can be linearized to find the inverse function allowing to calculate the EMF as function of the temperature. All data are presented in Tab. 2.

Tab. 2: Identified thermoelectric couples

\begin{tabular}{|c|c|c|c|}
\hline Couple & Transformation & Linearized equation & $\mathrm{R}^{2}$ \\
\hline \multirow{2}{*}{$\mathrm{K}+/ \mathrm{Ti}$} & $(\mathrm{mV}) \rightarrow\left({ }^{\circ} \mathrm{C}\right)$ & $12.290 \times \mathrm{V}-245.468$ & 0.99998 \\
\cline { 2 - 4 } & $\left({ }^{\circ} \mathrm{C}\right) \rightarrow(\mathrm{mV})$ & $0.081 \times \mathrm{T}+19.974$ & 0.99997 \\
\hline \multirow{2}{*}{$\mathrm{K}-/ \mathrm{Ti}$} & $(\mathrm{mV}) \rightarrow\left({ }^{\circ} \mathrm{C}\right)$ & $-27.162 \times \mathrm{V}-215.383$ & 0.99999 \\
\cline { 2 - 4 } & $\left({ }^{\circ} \mathrm{C}\right) \rightarrow(\mathrm{mV})$ & $-0.037 \times \mathrm{T}-7.929$ & 0.99999 \\
\hline \multirow{2}{*}{$\mathrm{K}+/ \mathrm{K}-$} & $(\mathrm{mV}) \rightarrow\left({ }^{\circ} \mathrm{C}\right)$ & $0.041 \times \mathrm{V}+0.062$ & 0.99956 \\
\cline { 2 - 4 } & $\left({ }^{\circ} \mathrm{C}\right) \rightarrow(\mathrm{mV})$ & $24.468 \times \mathrm{T}-1.349$ & 0.99956 \\
\hline
\end{tabular}

\subsection{Cutting conditions for orthogonal cutting tests}

Cutting forces quantification is necessary to establish the intensity of the heat fluxes flowing into the machined surface. Indeed, the energy consumption Pc during cutting is the product of the cutting speed $V_{c}$ and the cutting force Fc according to equation (2).

$$
\mathrm{P}_{\mathrm{c}}=\mathrm{F}_{\mathrm{c}} \times \mathrm{V}_{\mathrm{c}}
$$

Therefore, it is possible to define heat $Q_{w}$ carried away by the workpiece as expressed in equation (3).

$$
\mathrm{Q}_{\mathrm{W}}=\mathrm{B} \times \mathrm{P}_{\mathrm{c}}
$$

With B the total partition energy (\%), depending of kinematic parameters and thermal diffusivity of the material. Orthogonal cutting tests are performed on a DMG DMC 85V CNC machine equipped with linear motors. The material used is a hot rolled and annealed Ti-6Al-4V. Mechanical

\begin{tabular}{|c|c|c|c|c|c|c|}
\hline $\begin{array}{c}\mathrm{Rm} \\
(\mathrm{MPa})\end{array}$ & \multicolumn{2}{|c|}{$\begin{array}{l}\text { Re } 0.2 \% \\
\quad(\mathrm{MPa})\end{array}$} & \multicolumn{2}{|c|}{$\begin{array}{c}\text { Maximum } \\
\text { strain at break }\end{array}$} & \multicolumn{2}{|c|}{$\begin{array}{c}\text { Fracture } \\
\text { Toughness } \\
(\mathrm{Mpa} \sqrt{\mathrm{M}})\end{array}$} \\
\hline 964 & \multicolumn{2}{|c|}{881} & \multicolumn{2}{|c|}{$13 \%$} & \multicolumn{2}{|c|}{68} \\
\hline $\mathrm{Ti}$ & C & $\mathrm{N}$ & $\mathrm{Fe}$ & $\mathrm{Al}$ & V & 0 \\
\hline 89.144 & 0.015 & 0.006 & 0.18 & 6.51 & 3.99 & 0.17 \\
\hline
\end{tabular}
properties are listed in Tab. 3.

Tab. 3: Ti-6Al-4V mechanical properties and composition

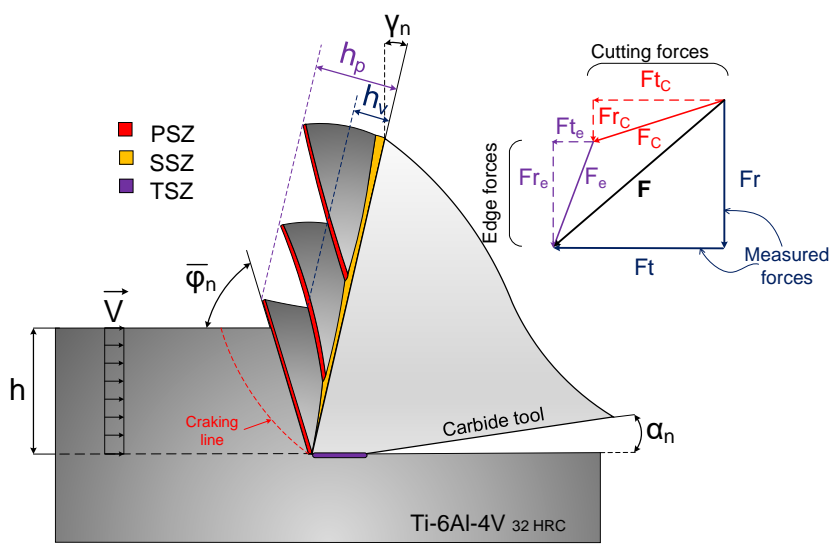

Fig. 5: Serrated chip formation scheme for Ti-6Al-4V orthogonal cutting and cutting forces decomposition

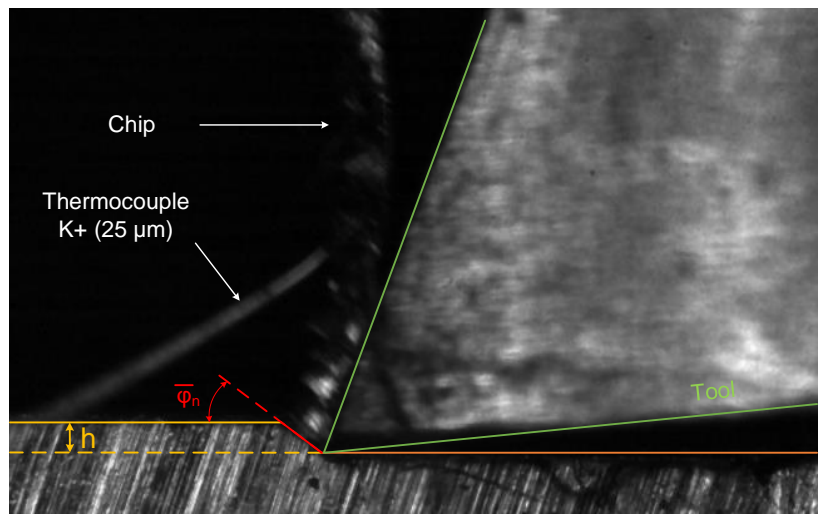

Fig. 6: K+ thermocouple carried out into the chip (Recorded with high-speed camera)

The Fig. 5 represents the schematic serrated chip in orthogonal cutting, as observed in Fig. 6 that could occur 
under most of the cutting conditions while machining Ti-6Al$4 \mathrm{~V}$ due to its low thermal conductivity and high hardness. The chip thickness varies with the uncut chip thickness $h$ and the rake angle $\gamma_{n}$. It is assumed that the average value of the chip thickness $\overline{h_{c}}$ is the arithmetic mean of both the peak height $h_{p}$ and the valley height $h_{v}$. Due to shear instability, the shear angle value varies in accordance to the serration frequency. The average value of the normal shear angle $\overline{\varphi_{\mathrm{n}}}$ will be taken into account in the present work. The cutting velocity is $V_{c}=120 \mathrm{~m} / \mathrm{min}$ and kept constant for all tests.

As shown in Fig. 5, measured forces (Ft and Fr) includes both the forces due to shearing effect on the primary shear zone, and the forces in tertiary deformation zone due to ploughing and spring back phenomenon behind the cutting edge. In consequence, as exposed in [Armarego 1985], the global cutting forces are decomposed into a cutting effect and an edge effect described in equations (4) and (5):

$$
\begin{aligned}
& \mathrm{Ft}=\mathrm{Ft}_{\mathrm{c}}+\mathrm{Ft}_{\mathrm{e}} \\
& \mathrm{Fr}=\mathrm{Fr}_{\mathrm{c}}+\mathrm{Fr}_{\mathrm{e}}
\end{aligned}
$$

Tab. 4 summarizes the cutting conditions and forces measured during the tests, comprising more than 100 orthogonal cutting tests. Each cut condition C.C was performed at least 3 times to compute their average and quantify the standard deviation of the measurement. Forces values are normalized to a unitary cutting width $b=1 \mathrm{~mm}$.

As shown in Fig. 7(a) and Fig. 7 (b), the tangential cutting forces Ft vary linearly with the uncut chip thickness $h$. A linear extrapolation to an uncut chip thickness of $h=0 \mathrm{~mm}$ allows to estimate the tangential force Fte resulting from the contribution of the cutting edge radius $r_{\beta}$ and work materia springback on the flank face. Since the edge radius $r_{\beta}$ is identical for both tools $(15 \mu \mathrm{m})$, the Fte values are almost identical. This observation is in accordance with prior work [Wyen 2010]. The Ft increase rate is characterized by the specific cutting pressure $\mathrm{Kt}$ and depends on the rake angle $\mathrm{Yn}_{\mathrm{n}} \quad$ Thus, $\mathrm{Kt}\left(\mathrm{Y}_{\mathrm{n}}=0^{\circ}\right)=1582 \mathrm{MPa}$ and $\mathrm{Kt}\left(\mathrm{Yn}_{\mathrm{n}}=20^{\circ}\right)=1457 \mathrm{MPa}$, corresponding to a noticeable decrease of $8 \%$. In the case of $\gamma_{n}=0^{\circ}$, uncut chip thicknesses below $0.040 \mathrm{~mm}$ induce severe ploughing phenomenon leading to a feed force increase.

\begin{tabular}{|c|c|c|c|c|c|c|}
\hline C.C & $\begin{array}{l}V_{n} \\
\left({ }^{\circ}\right)\end{array}$ & $\begin{array}{c}\mathrm{h} \\
(\mathrm{mm})\end{array}$ & $\begin{array}{l}\mathrm{Ft} \\
(\mathrm{N})\end{array}$ & $\begin{array}{l}\text { Fr } \\
(\mathrm{N})\end{array}$ & $\begin{array}{l}\text { Fte } \\
(\mathrm{N})\end{array}$ & $\begin{array}{l}\text { Fre } \\
(\mathrm{N})\end{array}$ \\
\hline$A 1^{(a)}$ & \multirow{5}{*}{0} & 0.02 & $65 \pm 6$ & $106 \pm 9$ & \multirow{5}{*}{28} & \multirow{5}{*}{73} \\
\hline A2 & & 0.04 & $91 \pm 3$ & $73 \pm 3$ & & \\
\hline A3 & & 0.06 & $116 \pm 15$ & $83 \pm 6$ & & \\
\hline A4 & & 0.08 & $160 \pm 1$ & $109 \pm 13$ & & \\
\hline $\mathrm{A} 5^{(\mathrm{a}, \mathrm{b})}$ & & 0.10 & $190 \pm 1$ & $114 \pm 1$ & & \\
\hline$B 1^{(a)}$ & \multirow{5}{*}{20} & 0.02 & $54 \pm 2$ & $70 \pm 3$ & \multirow{5}{*}{31} & \multirow{5}{*}{60} \\
\hline B2 & & 0.04 & $91 \pm 2$ & $83 \pm 2$ & & \\
\hline B3 & & 0.06 & $120 \pm 1$ & $89 \pm 1$ & & \\
\hline B4 & & 0.08 & $146 \pm 1$ & $92 \pm 3$ & & \\
\hline$B 5^{(a, b)}$ & & 0.10 & $175 \pm 3$ & $72 \pm 1$ & & \\
\hline & & itior & & & mea & ments \\
\hline
\end{tabular}

Tab. 4: Measured cutting forces

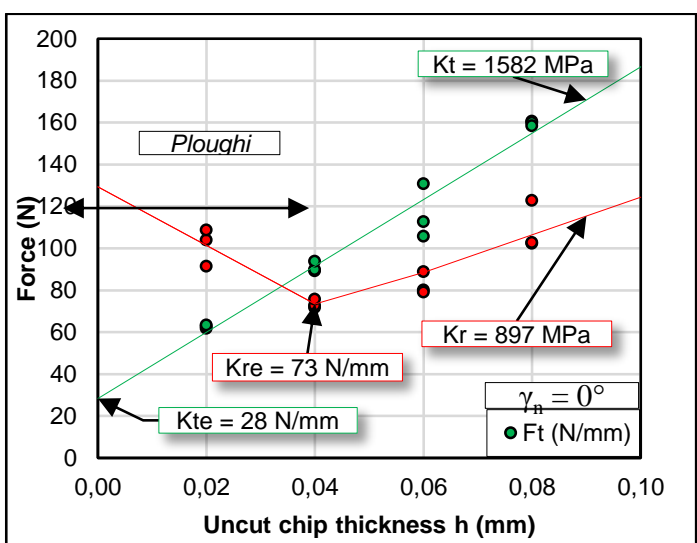

(a)

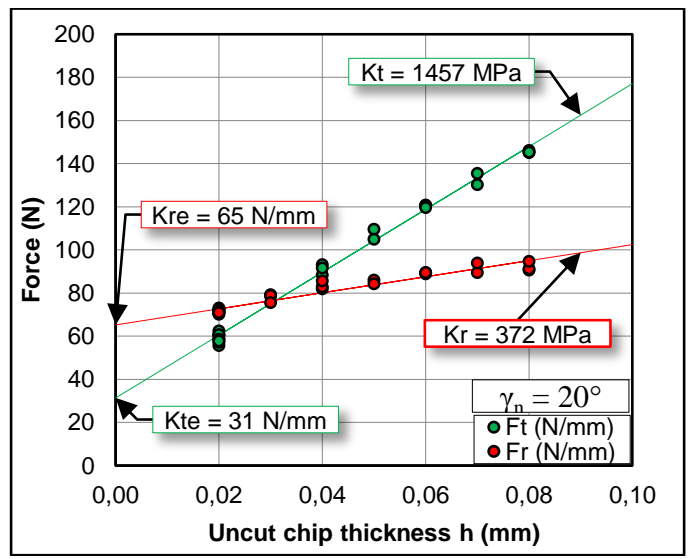

(b)

Fig. 7: Cutting forces for: (a) $\gamma_{n}=0^{\circ}$ and (b) $\gamma_{n}=20^{\circ}$

\subsection{Experimental Cutting temperatures in orthogonal cutting}

The temperature beneath the machined surface is measured with the very thin $\mathrm{K}_{+}$thermocouple $(25 \mu \mathrm{m}$ diameter) welded on the side of the specimen as presented in Fig. 8. Successive cuts at a constant uncut chip thickness $\mathrm{h}$ allow building the thermal gradient below the machined surface; and this had been made for different cutting conditions, i.e. A1, B1, A5, and B5 shown in Chyba! Nenalezen zdroj odkazů. (a), (b), (c), and (d). The $T_{\max }$ curve represents the maximal temperature reached for several depth underneath the machined surface, independently of the time. 


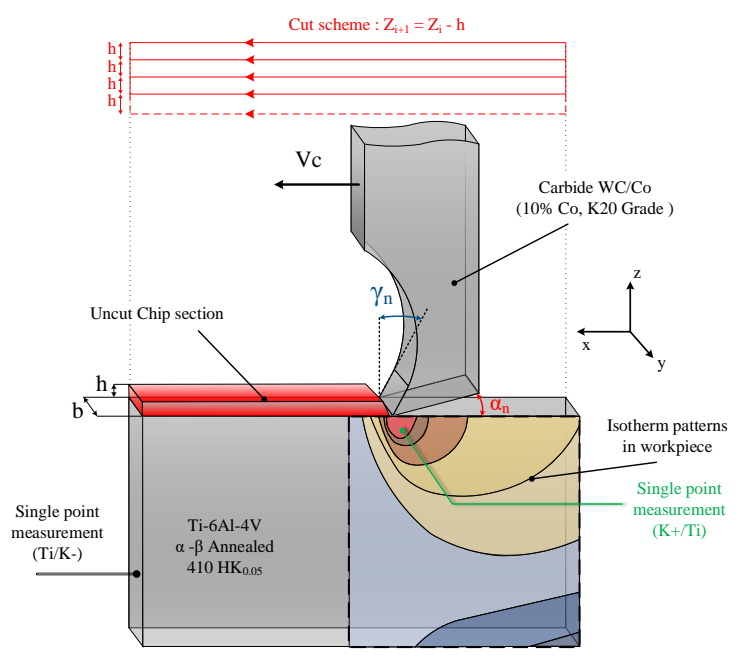

Fig. 8: Tool cuts scheme with theoretical thermal distribution arising from an analytical solution and the thermocouple legs ( $K+$ and $K$-) locations on the workpiece

The increase in temperature is very localized. Indeed, for all cutting conditions, only the first $100 \mu \mathrm{m}$ suffer a significant temperature increase of at least twice the workshop temperature. Due to low thermal conductivity and thermal diffusivity, the affected depth never exceeds $200 \mu \mathrm{m}$ for all cutting conditions. The cooling speed of the surface is very low compared to the heating speed.

(a)
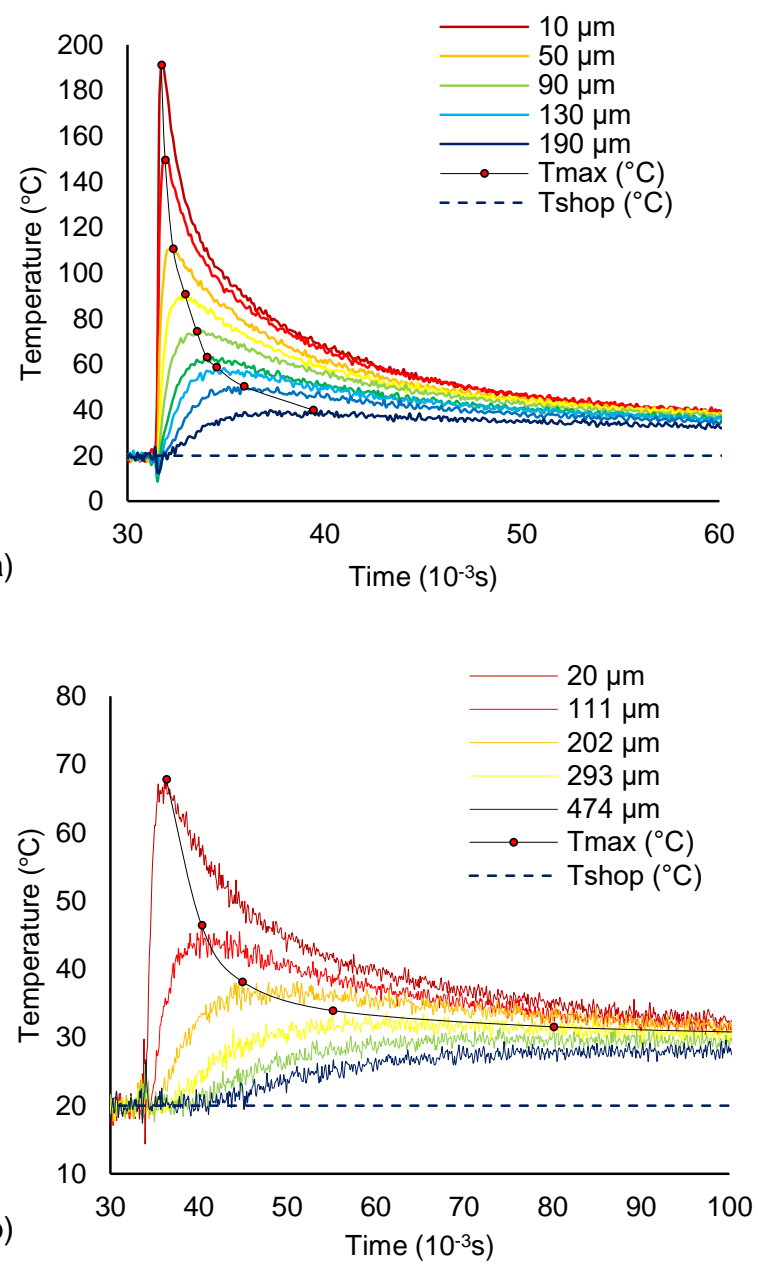

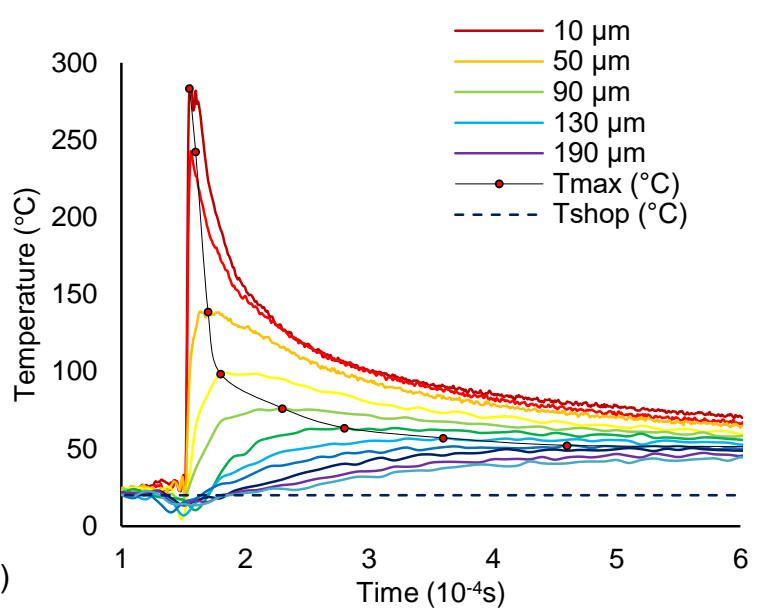

(d)

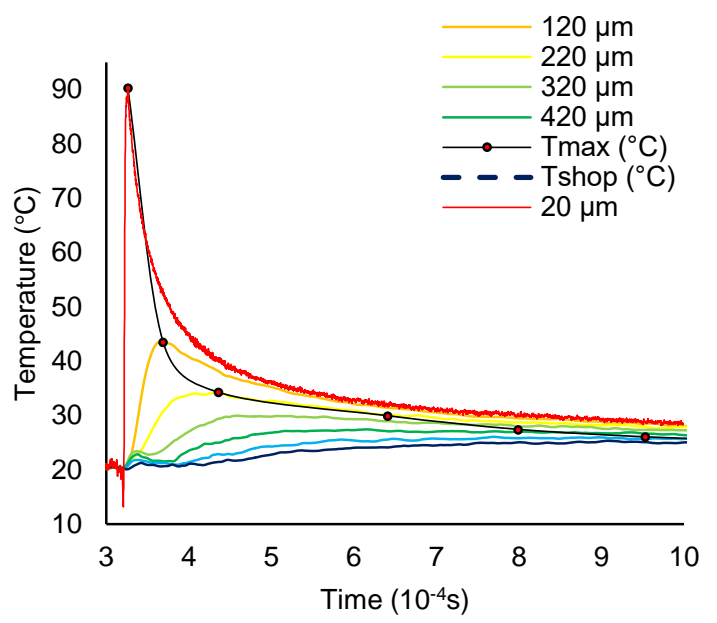

Fig. 9: Temperature beneath machined surface measured with $K+$ thermocouple: (a) $h=20 \mu \mathrm{m} \&$ $y n=20^{\circ}-$ (b) $h=100 \mu m \& y n=20^{\circ}-$ (c) $h=20 \mu m \&$ $y n=0^{\circ}-(d) h=100 \mu m \& y n=0^{\circ}$

Fig. 10 summarizes the maximal recorded temperatures located at a distance of $10-20 \mu \mathrm{m}$ from the machined surface depending on the rake angle and the uncut chip thickness. The maximum reached temperature is highly dependent of the uncut chip thickness and the rake angle. These temperature gaps are justified in section $\underline{3}$.

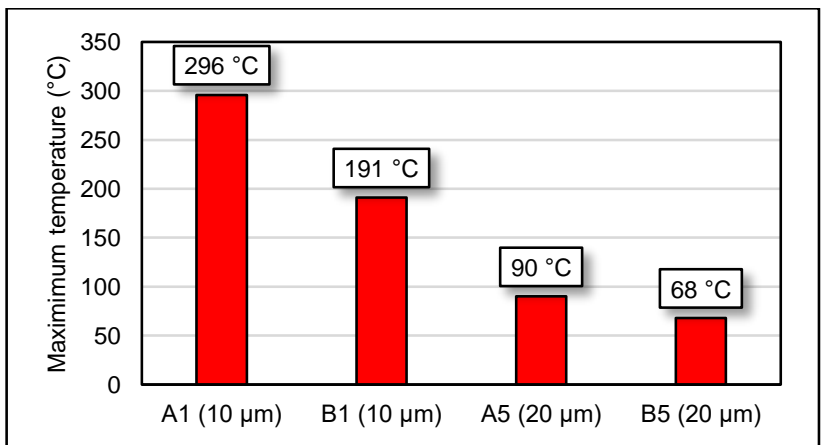

Fig. 10: Maximum temperature depending on the rake angle and the uncut chip thickness

More recently, [Sun 2014] performed peripheral milling cutting tests, recording surface temperature with a semiartificial thermocouple. They point out that for small uncut chip thickness, between $40 \mu \mathrm{m}$ to $0 \mu \mathrm{m}$ (down milling configuration), the surface temperature vary from $350^{\circ}$ to $422^{\circ}$ for a $10^{\circ}$ rake angle tool and $V_{c}=120 \mathrm{~m} / \mathrm{min}$. These results, of the same order of magnitude as the results obtained through orthogonal cutting tests in this study, 
show nevertheless that the surface temperatures in $3 D$ regime are slightly higher that can be due to thermal cycling.

\subsection{Experimental heating rates in orthogonal cutting}

Thanks to the very low response time of the thermocouple, the heating rate during temperature increase becomes accessible. For the cutting conditions A5 and B5, respectively shown in Fig. 11 (a) and (b), the temperature and heat velocity have been measured into the primary shear zone with high accuracy.

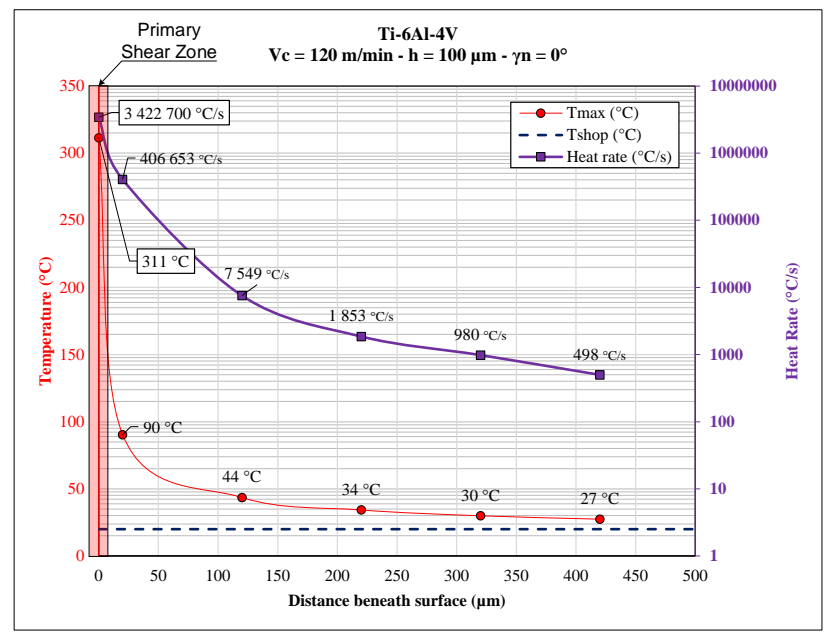

(a)

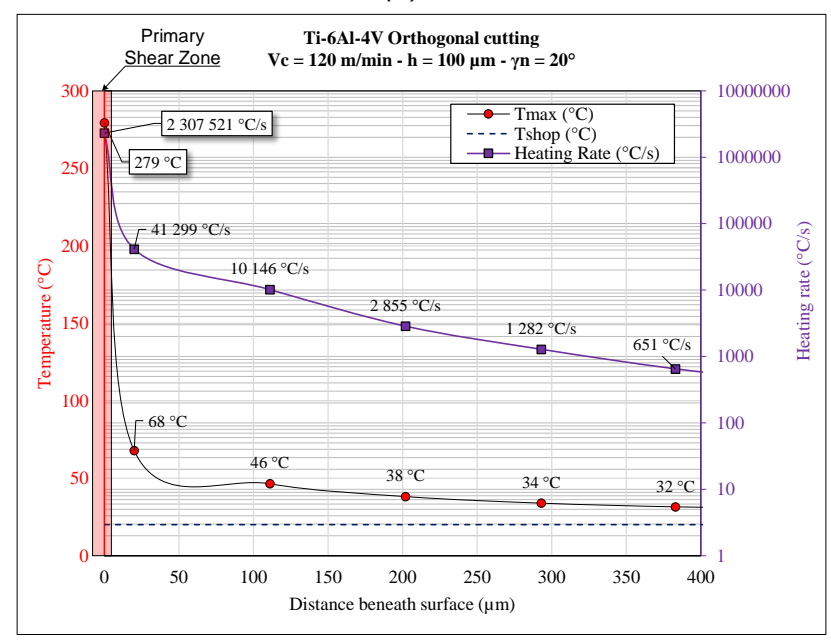

(b)

Fig. 11: Temperature and heating rate beneath the machined surface and into PSZ for: (a) $h=100 \mu \mathrm{m}$ and $\gamma_{n}=0^{\circ}$, and (b) $h=100 \mu \mathrm{m}$ and $\gamma_{n}=20^{\circ}$

The temperature intensity measured experimentally inside the primary shear zone can be compared to prior work of [Cotterell 2008] where they predicted analytically the average shear band temperature $\theta_{\mathrm{s}}$ using [Shaw 2005] thermal equations.

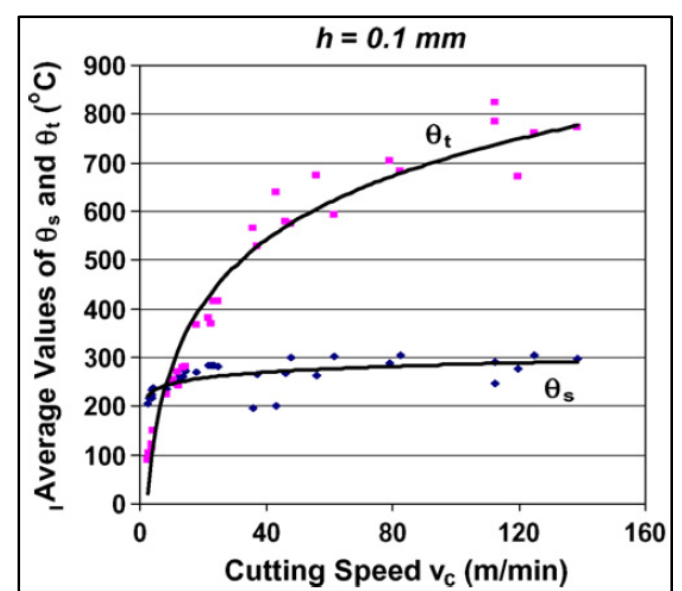

Fig. 12: Predicted shear band and rake face temperatures [Cotterell 2008]

From Fig. 12, and at least for $V_{c}=120 \mathrm{~m} / \mathrm{min}$, the experimental temperature rise measured in this work inside the PSZ is in agreements with the predicted temperatures arising from Shaw's theory.

More recently, [Bai 2017] models the PSZ by a non-zero and asymmetric thickness band, and shows by analytical computation, and by integrating a modified JC law [Calamaz 2008], that the mean temperature for a cutting condition $\mathrm{h}=0.1 \mathrm{~mm}$ and $\mathrm{Vc}=120 \mathrm{~m} / \mathrm{min}$ vary from $20^{\circ} \mathrm{C}$ to $350^{\circ} \mathrm{C}$. Numerical simulations show that the temperature into the PSZ varies, for this same condition, from $20^{\circ} \mathrm{C}$ to $700^{\circ} \mathrm{C}$ near the tool-chip interface.

\section{DISCUSSION}

\subsection{Influence of the uncut chip thickness on the surface heat generation}

The temperature measurements show that the surface temperature increases gradually with the uncut chip thickness decrease, as show in Fig. 10. This is correlated with the feed rate from a global machining point of view. This phenomenon is driven by two mechanisms. The first one is the shear angle $\varphi_{n}$ dependency with $h$, which decreases gradually with $\mathrm{h}$. Thus, the primary shear plane, modelled by a moving heat band, is closer to the final surface. To resume, at equal thermal energy, the thermal diffusive power of the primary shear band is increased by a higher shearing plan angle.

The second mechanism responsible for the temperature increase is the ability to evacuate the thermal energy within the chip, rather than in the surface. The greater the thickness of the chip, the more calories are evacuated.

\subsection{Influence of the cutting edge geometry on the surface heat generation}

The present study shows that the rake angle has an important influence on the cut stability at low tool engagement (Fig. 7), but also that the temperature increases as the rake angle decreases (Fig. 10). Indeed, decreasing the rake angle decreases the shear angle, bringing the shear band closer to the finished surface. In addition, the decrease of the rake angle intensifies the shear deformations $\gamma$ and its associate deformation rate $\frac{\mathrm{d} \gamma}{\mathrm{dt}}$ in the primary shear zone, leading to a temperature increase. In addition, the springback, important with titanium alloy such as Ti-6Al-4V, causes a temperature increase due to the intense friction generated along the tool 
flank. This phenomenon can be assimilated to a moving heat band shown in Fig. 13.

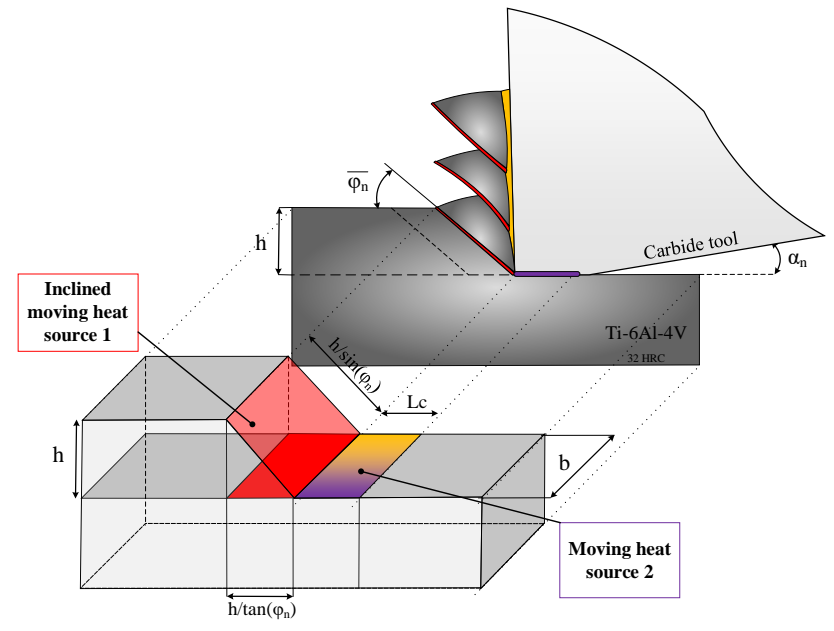

Fig. 13: Moving heat sources scheme

\section{CONLUSION}

In this research work, a new experimental setup for punctual temperature measurement using a single miniaturized thermocouple was developed and implemented to characterize the temperature and the heating rates as a function of the cutting parameters, such as the uncut chip thickness and the rake angle.

The experimental results showed that:

- $\quad$ The surface temperature is highly dependent on the uncut chip thickness. Thus, a decrease in the uncut chip thickness systematically causes an increase of the surface temperature. Therefore, particular attention must be paid concerning the selection of the feed rate $\mathrm{f}_{\mathrm{z}}$ during machining, especially during the finishing machining operations,

- The cutting edge geometry has a significant influence on the cutting stability as well as on the temperature rise of the machined surface. Decreasing the rake angle results in an increase of the surface temperature,

- Therefore, tools with a reduced rake angle should always be used in combination with high feed rates. This is a favourable case for roughing operations. Conversely, operations with low cutting engagement must always use special cutting angles to ensure good cutting stability and low thermal load on the machined surface.

Further investigations, based on these experimental results, will be carried out in order to identify the equivalent heat flow involved in machining as a function of a wide range of process parameters. This work will identify the major contributors to surface integrity deterioration and will allow the selection of the most efficient set of parameters to guarantee surface reliability.

\section{ACKNOWLEDGMENT}

The authors would like to thank the involvement of Airbus and the OMIMI manufacturing R\&T team in the project, especially Samuel DROUVROY and Anne Laure LAFLY. The authors acknowledge as well as the IACM team, especially Laurent PINTO for their valuable technical support.

\section{REFERENCES}

[Armarego 1985] Armarego E.J.A, and Whitfield R.C, Computer Based Modelling of Popular Machining Operations for Force and Power Prediction, CIRP Annals, 1985

[Attia 2002] Attia M. H., Cameron A., and Kops L., Distortion in Thermal Field Around Inserted Thermocouples in Experimental Interfacial Studies, Journal of Manufacturing Science and Engineering, 2002

[Bai 2017] Bai W., R. Sun, A. Roy, and V. V. Silberschmidt, Improved analytical prediction of chip formation in orthogonal cutting of titanium alloy Ti6Al4V, International Journal of Mechanical Sciences, vol. 133, pp. 357-367, Nov. 2017

[Calamaz 2008] Calamaz M , Coupard D , Girot F, A new material model for 2D numerical simulation of serrated chip formation when machining titanium alloy $\mathrm{Ti}-6 \mathrm{Al}-4 \mathrm{~V}$. Int $\mathrm{J}$ Mach Tools Manuf 2008;48:275-88.

[Cotterell 2008] Cotterell M. and Byrne G., Characterisation of Chip Formation during Orthogonal Cutting of Titanium Alloy Ti-6Al-4V, CIRP Journal of Manufacturing Science and Technology High Performance Cutting, 2008

[Davies 2007] Davies M.A., Ueda T., M'Saoubi R., Mullany B., and Cooke A.L., On the measurement of temperature in material removal processes, CIRP Annals, 2007

[Hahn 1951] Hahn R., On the temperature developed at the shear plane in the metal cutting process, Journal of Applied Mechanics-Transactions of the ASME, 1951

[Boothroyd 1963] Boothroyd G., Temperatures in orthogonal metal cutting, Proceedings of the Institution of Mechanical Engineers, 1963

[Komanduri 2000] Komanduri R. and Hou Z.B., Thermal Modeling of the Metal Cutting Process: Part I - Temperature Rise Distribution Due to Shear Plane Heat Source, International Journal of Mechanical Sciences, 2000

[Shaw 2005] Shaw M.C., Metal Cutting Principles, 2nd ed. Oxford Series on Advanced Manufacturing 3. New York: Oxford University Press, 2005

[Stephenson 1992] Stephenson D. A. and Ali A., Tool Temperatures in Interrupted Metal Cutting, Journal of Engineering for Industry, 1992

[Sun 2014] Y. Sun, J. Sun, J. Li, and Q. Xiong, An experimental investigation of the influence of cutting parameters on cutting temperature in milling Ti6Al4V by applying semi-artificial thermocouple," Int J Adv Manuf Technol, vol. 70, no. 5-8, pp. 765-773, Feb. 2014

[Trigger 1951] Trigger K.J., An analytical evaluation of metal-cutting temperatures, Trans. ASME, 1951

[Wyen 2010] Wyen C.F., and Wegener K., Influence of cutting edge radius on cutting forces in Machining Titanium, CIRP Annals, 2010 